\title{
Relationship of Serum Tau Levels with Cognitive Functions and Factors Affecting the Cognitive Function Decrease in Parkinson's Disease Patients
}

\section{Meldayeni Busra ${ }^{1 *}$ Yuliarni Syafrita ${ }^{2}$, Hendra Permana ${ }^{2}$}

${ }^{1}$ PPDS Neurology Faculty of Medicine, UNAND, Padang

${ }^{2}$ Staff of the Neurology Section, Faculty of Medicine, UNAND, Padang

\author{
A R T I C L E I N F O \\ Keywords: \\ Cognitive function \\ Parkinson's disease \\ Serum tau levels \\ *Corresponding author: \\ Meldayeni Busra \\ E-mail address: \\ alifhaykal.mb@gmail.com
}

All authors have reviewed and approved the final version of the manuscript.

https://doi.org/10.32539/bsm.v5i6.317

\begin{abstract}
A B S T R A C T
Background: Cognitive impairment is a non-motor symptom of Parkinson's disease (PD) which occurs as the disease progresses and affects quality of life. Many efforts have been developed in early detection of cognitive disorders, one of which is the examination of tau protein biomarkers, where the tau protein that undergoes pathological changes to form neurofibrillary tangles (NFTs) is found in Alzheimer's disease and PD and plays a role in cognitive impairment. However, the role of tau in PD is still controversial. This study aims to assess the relationship between serum tau levels and cognitive function and the factors that affect cognitive function in PD patients. Methods: This cross-sectional design was conducted at the RSUP DR. M Djamil Padang. During the period March to August 2020, 62 research subjects were obtained. Cognitive function examination was carried out by using the MoCA-Ina test and examination of serum tau levels using the Elisa method. The relationship between categorical variables was tested by Chi square and differences in serum tau levels in the group with and without cognitive impairment were tested with the Mann Whitney test, considered statistically significant if the $p$ value $<0.05$. Results: With Moca Ina examination, it was found that $67.7 \%$ of patients had impaired cognitive function. The mean serum tau level was $198.004 \pm 162.69 \mathrm{ng} / \mathrm{L}$. There was a significant relationship between education level and degree of disease with cognitive function $(p<0.05)$ and there was no difference in mean serum tau levels between groups with and without cognitive impairment. Conclusion: There is a significant relationship between education level and degree of disease with cognitive function and there is no difference in mean serum tau protein levels between the cognitive impaired group and the cognitive normal group.
\end{abstract}

\section{Introduction}

Cognitive function is the main human capital in the activities of daily life. Decrease and impaired cognitive function can occur due to damage to brain structure and function which can be caused by increasing age, degenerative diseases, vascular and autoimmune diseases.15 Parkinson's disease (PD) is a neurodegenerative disorder that has non-motor symptoms in the form of cognitive dysfunction 6,19

It is estimated that about $20-40 \%$ of people with Parkinson's experience cognitive impairment. This disorder can appear with varying symptoms as the disease progresses, from mild symptoms called Parkinson's Disease-Mild Cognitive Impairment (PDMCI) which occurs in $25-30 \%$ to severe symptoms, namely Parkinson's Disease Dementia (PDD) which occurs $30 \%$ to $80 \%$ of cases 4,26

Data from a systematic review in 2010 on 776 Parkinson's patients through 6 cross-sectional studies and 2 prospective studies found a prevalence of PD MCI of $26.7-30 \% .3$ The study, which was conducted at the 
neurological polyclinic of Kandou Hospital Manado, found 27 out of 31 Parkinson's patients experienced cognitive dysfunction, especially in male patients in the 61-70 year age group. ${ }^{24}$ Research at Saiful Anwar Hospital Malang found that 20\% of Parkinson's patients experienced cognitive dysfunction based on the Mini Mental State Examination (MMSE) and Clock Drawing Test (CDT) examination, especially in Hoehn and Yahr stage II. ${ }^{1}$ Meanwhile, the research conducted at the hospital. DR. M. Djamil Padang in 2019 found $46.7 \%$ of 30 Parkinson's patients experienced cognitive impairment through the MMSE examination. 9

Tau protein is a protein that normally functions in the stabilization of microtubules, cell membranes and regulation of axonal transport. The tau protein that undergoes pathological changes will experience aggregation to form neurofibrillary tangles known as taupati. Tau dysfunction results in disruption of normal tau function which results in deterioration of the interneurone synaptic transmission. Previously, taupati was reported to play an important role in the pathogenesis of $\mathrm{AD}$, but recently it has also been suspected of having a role in PD. 20 There are genetic factors that play quite a complex role as a risk factor for $\mathrm{PD}$, including mutations in the MAPT gene (Microtubule Associated Protein Tau) resulting in pathological aggregation of tau protein which results in a rapid degeneration process and neuron cell death. This MAPT gene mutation is one of the factors that influence the development of dementia in PD. 14, 8

Studies by Mollenhauer in 2016, and Liorens F in 2018 showed an increase in tau protein levels in Parkinson's disease dementia compared to nondementia PD, however the research of Lukasiewicz (2018) and Alves (2010) showed no relationship between tau protein levels and cognitive function in patients $\mathrm{PD} 2,12,13,16$

Research conducted by Horvath (2013) shows a higher increase in braak tau stages is associated with decreased cognitive function in PD patients. 10 While the study by Joseph $\mathrm{R}$ winner showed no significant difference between tau deposits in controls, PD patients with normal cognitive (Parkinson's Disease Cognitive normal / PDCN) and PD MCI as measured by tau positron emission tomographic (PET) scanning (Winner et al. 2017 ) Several other studies have also shown controversial results.

Given the importance of the role of cognitive function in everyday life, efforts to detect cognitive dysfunction in Parkinson's patients should be detected as early as possible so that it can maintain the quality of life in Parkinson's patients.

Based on this background, the authors are interested in further investigating the relationship between serum tau levels and cognitive function as well as factors associated with decreased cognitive function in patients with Parkinson's disease.

\section{Method}

This study used a cross sectional design with a comparative descriptive approach. The study population was all patients with Parkinson's disease (PD) who went to the Neurology Polyclinic DR. M. Djamil and several other networking hospitals in the city of Padang. Samples were taken by consecutive sampling method that met the inclusion and exclusion criteria. The inclusion criteria were Parkinson's patients who had been diagnosed clinically based on Hughes' criteria and were willing to participate in this study. Meanwhile, patients with secondary Parkinson's disease and diabetes mellitus were excluded from this study. There were 62 research subjects, where in the early stages, demographic and clinical characteristics of the subjects were recorded, such as age, sex, education, disease duration, and disease stage based on Hoehn and Yahr's criteria. Cognitive function is classified into two groups, namely undisturbed and disturbed based on the Moca Ina examination. Statistical analysis was performed computerized with SPSS 22.0 for windows. Continuous variables were shown as mean \pm standard deviation (SD) and analysis of the relationship between variables was carried out by using the chi square test and analysis of the relationship between serum tau levels and cognitive function was performed using the Mann Whitney test with $\mathrm{p}$ value $<0.05$ was considered statistically 
significant.

\section{Results and discussion}

During the period March to August 2020, there were 62 study subjects, of which $56.5 \%$ were men with a mean age of $64,45 \pm 8.4$ years and a disease duration of $6.35 \pm 5.29$ years. With the classification of education levels are grouped into 2 groups, namely, higher education which includes higher education, and low, namely secondary school education and below. Based on Moca Ina's examination, it was found that $67.7 \%$ of the subjects had cognitive impairments and $32.3 \%$ had normal cognitive impairments. The basic characteristics of PD patients are shown in Table 1.

The assessment of cognitive function is based on the examination of the Moca Ina score, where a score of less than 26 is declared disturbed and a large score equal to 26 is declared not disturbed with a result of $67.7 \%$ with impaired cognitive function. This result is quite large compared to other studies. The report on the frequency of cognitive impairment varies considerably from several previous studies which are influenced by the number of samples, demographics, factors of therapy at the time of the examination, characteristics of the disease, the neuropsychological tests used, and the research design used. ${ }^{3}$

Bivariate analysis was performed to look for factors that influence cognitive decline in patients with Parkinson's disease. In this study, there was a significant difference between education level and disease degree with cognitive function $(\mathrm{p}<0.05)$ and there was no significant difference between serum tau levels, age, sex, duration of illness and cognitive function in patients with Parkinson's disease. The relationship between serum tau levels and cognitive function is presented in table 2 and the relationship between variables is presented in table 3 .

The difference in tauserum levels between the group with cognitive impairment and the group with normal cognitive function is presented in table 2 .

Serum tau levels in patients with PD are inconsistent. In this study, there was no difference in the mean serum $\mathrm{t}$-tau protein levels between the group with cognitive impairment and the group with normal cognitive function. These results are consistent with several previous studies, namely research by Montine $\mathrm{TJ}$ et al, which showed that there was no change in $\mathrm{t}$ tau levels between PD patients with normal cognitive, PD-CIND and PDD, but there was a significant decrease in levels of P181-tau (p-tau). on PD-CIND with $\mathrm{p}$ $<0.001 .{ }^{17}$ Previous research conducted by Compta et al in 2009, also showed an insignificant relationship between $t$ tau and $p$ tau values with cognitive, but there is a tendency to increase $t$ tau and $p$ tau associated with verbal and naming learning disorders in PDD patients. 7 In contrast to research conducted by Salama et al in 2018, which found that serum tau levels in PD and Alzheimer's Disease / $\mathrm{AD}$ patients increased significantly compared to healthy controls and other studies on cerebrospinal fluid showed that most tau values were normal in PD-MCI patients. and inconsistent results for PDD. Several studies have also reported a mild to moderate increase in $\mathrm{t}$-tau values in PDD compared to PD without dementia and normal controls. ${ }^{2}$

Table 3 shows that there is a significant difference between education level and disease degree with cognitive function. The relationship between education level and cognitive function in patients with Parkinson's disease is in accordance with previous research by Jin Lin S et al in 2018. These results are consistent with the concept of cognitive reserve, where education can induce neuroprotective effects in neurodegenerative processes. Education will strengthen plasticity and flexibility in neural circuits which will provide more neural resources that can improve brain function. ${ }^{11}$

Hoehn and Yahr's (HY) stage which indicates the progression of Parkinson's disease also shows a significant difference. These results are in accordance with the research conducted by Horvath (2013) which shows that a higher increase in braak tau stages is associated with a decrease in cognitive function in PD patients (Horvath, 2013). Another study by Jancovic et al reported that patients with grade I HY had better cognitive function compared to HY grade II especially in 
the memory domain, although this was not seen in the other domains. The relationship between degree of disease and cognitive function is still inconsistent, as evidenced by several studies including by Weintraub et al which showed that there was no significant relationship between PD patients with HY II or more with impaired cognitive function. 23

The gender factor in this study did not show significant results, this is almost the same as the research conducted by Jin Lin S et al in 2018 which showed inconsistent results from examining cognitive function in men and wome ${ }^{11}$. And this is different from previous research by Cereda et al in 2016 which showed a higher prevalence of cognitive impairment occurred in men and over 60 years of age. In theory, it is assumed that there is a higher risk of cognitive impairment in male patients with Parkinson's disease caused by the synucleinopathic process and cortical pathological processes of lewy bodies in men than in women, so that male patients with Parkinson's disease are at higher risk. cognitive impairment to dementia is twice as high as women. This is also associated with the presence of estrogen exposure which has a neuroprotective effect in women. Another possibility is that there is a direct effect of genetic factors related to sex chromosomes that affect the process of differentiation of development in the nigrostriatal pathway and its connection related to gender, besides that the risk factors for environmental exposure are also thought to be higher in men than in women. ${ }^{5}$
In this study, the age factor did not show a significant difference, but this may be due to the number of patients who were mostly> 60 years old (only 6 people were $<60$ years old), so that the age difference on cognitive function did not reflect the relationship between age and cognitive function. absolutely. Where in previous studies age had significant risk factors for cognitive decline, such as the study of Wan Mohammad WNA et al (2015) which showed a decrease in cognitive function using cut-off age at 77 years 8, 11, 25

The duration or duration of illness is an important risk factor for cognitive decline in patients with Parkinson's disease, as seen from longitudinal studies and previous meta-analyzes. Several studies have shown an association between the prevalence of dementia and duration of disease. The CamPaIGN study, reported the prevalence of dementia increasing from $15 \%$ to $20 \%$ after 5 years and to $46 \%$ after 10 years. however this is not proven in this study. 18, 21, 25

Research with cross sectional method is one of the limitations of this study, where a study with a cohort design may be able to provide more representative results, such as by regularly evaluating serum tau levels in PD patients. In addition, it is necessary to identify other factors that affect cognitive function such as genetic factors, diagnostic markers such as beta amyloid deposition, alpha synuclein and tau protein including t tau and $\mathrm{p}$ tau which may play a role in the process of cognitive decline in Parkinson's disease.

Table 1. Basic Characteristics

\begin{tabular}{ll}
\hline Characteristics & Frequency (n= 62) \\
\hline Age, mean ( \pm SD ) & $64,45( \pm 8,425)$ \\
Median ( Min-maks ) & $64.50(35-78)$ \\
Gender, n(\%) & $35(56.5 \%)$ \\
Male & $27(43.5 \%)$ \\
Female & $6.35( \pm 5.29)$ \\
Duration of illness, mean ( \pm SD ) & $5(0.5-25)$ \\
Median (Min-maks) & \\
Stage of disease & $8(12.9 \%)$ \\
HY I &
\end{tabular}




\begin{tabular}{ll}
\hline HY II & $15(24.2 \%)$ \\
HY III & $27(43.5 \%)$ \\
HY IV & $9(14.4 \%)$ \\
HY V & $3(4.8)$ \\
Serum Tau level, Mean ( \pm SD $)$ & $198.004( \pm 164.695)$ \\
Median (Min-max) & $137.516(18.75-662.99)$ \\
Moca Ina Score, Mean ( \pm SD ) & $20.13( \pm 5.84)$ \\
Cognitive Function & \\
Not distrubed & $20(32.26 \%)$ \\
Annoyed & $42(67.74 \%)$ \\
\hline
\end{tabular}

Table 2. Relationship between serum tau levels and cognitive function

\begin{tabular}{lcccc}
\hline & n & $\begin{array}{r}\text { Serum t-tau levels } \\
\text { Median(min- max) }\end{array}$ & p \\
\hline The cognitive impaired group & 42 & $133.6(18.75-647.69)$ & 0.63 \\
Normal cognitive group & 20 & $146.8(27.56-662.99)$ & \\
\hline
\end{tabular}

Mann Whitney test

Table 3. Relationship of factors that affect cognitive function in patients with Parkinson's disease

\begin{tabular}{|c|c|c|c|c|c|c|}
\hline \multirow{2}{*}{ Influencing factors } & \multicolumn{2}{|c|}{ Cognitive } & \multirow{2}{*}{$\begin{array}{c}\mathbf{P} \\
\text { value }\end{array}$} & \multirow{2}{*}{ RO } & \multicolumn{2}{|c|}{ IK $95 \%$} \\
\hline & Annoyed & Not distrubed & & & Min & $\operatorname{Max}$ \\
\hline Gender & & & 0.349 & 0.592 & 0.197 & 1.780 \\
\hline Male & 22 & 13 & & & & \\
\hline Female & 20 & 7 & & & & \\
\hline Age & & & 0.302 & 2.00 & 0.528 & 7.569 \\
\hline$\geq 60$ years & 36 & 15 & & & & \\
\hline$<60$ years & 6 & 5 & & & & \\
\hline Duration of ilness & & & 0.874 & 1.091 & 0.373 & 3.187 \\
\hline$\geq 5$ years & 24 & 11 & & & & \\
\hline$<5$ years & 18 & 9 & & & & \\
\hline Education level & & & 0.011 & 4.143 & 1.341 & 12.798 \\
\hline Low & 29 & 7 & & & & \\
\hline High & 13 & 13 & & & & \\
\hline Degree of Disease & & & 0.044 & 3.056 & 1.011 & 9.239 \\
\hline Weight : HY $(3,4,5)$ & 30 & 9 & & & & \\
\hline Light: $\quad H Y(1,2)$ & 12 & 11 & & & & \\
\hline
\end{tabular}

Chi-square test

\section{Conclusion}

This study found a significant relationship between education level and degree of Parkinson's disease with cognitive function in patients with Parkinson's disease.
There were no differences in serum tau levels between groups with cognitive impairment and groups with normal cognitive function in PD patients and there was no relationship between gender, age and duration of illness with cognitive function in PD patients. It is 
necessary to look for the relationship between other factors such as characteristics with certain cognitive domains and other biomarkers that affect cognitive function with a more representative sample size.

\section{References}

1. Adhayani F, Listyaningrum D, Sjahrir H, 2014. Cognitive Disorders of Patients with Parkinson's Disease. Neurona vol 31 no 2.

2. Alves G,Padersen KF, Larsen JP. 2015. Biomarker for cognition impairment and dementia in Parkinson's disease. In Cognitive impairment and dementia in Parkinson's disease.Oxfor University Press chapter 11.17151

3. Caccappolo E and marder K, 2015. Epidemiology, diagnosis, and correlates of mild cognitive impairment in parkinson's disease. In Cognitive Impairment and Dementia in Parkinson's Disease. Ed 2nd. Chapter 16. Pp204-218

4. Caspel GC, Simuni T, Tosun TD,Wu IW,Zhang Y,Nalls M et al, 2017. Multiple Modality biomarker Prediction of Cognitive Impairment in prospectively followed de novo Parkinson disease. Plos one journal.pp.1-18

5. Cereda E, Cilia R,Klersy C, Siri C, pozzi B, Reali E , et al,2016. Dementia in Parkinson's disease : Is male gender a risk factor?. Elsevier. Parkinsonism and related disorders.

6. Collins LM and williams CH. 2016. The genetic basis of cognitive impairment and dementia in Parkinson's disease.Frontiers in Psychiatry.volume 7;89

7. Compta Y, Marti MJ, Ibarretxe BN. 2009. Cerebrospinal tau, phospho tau and beta amyloid and neuropsycological functions in perkinson's disease. Mov disord 24: 2203-22 10

8. Cosgrove J, alty JE, Jamieson S. 2018. Cognitive impairment in Parkinson's disease.British medical journal.0:0-9

9. Desravima MB, 2019. Hubungan derajat penyakit parkinson dengan gangguan fungsi kognitif menggunakan instrumen Mini mental state examination (MMSE). Scholar. Unand.ac.id.

10. Horvath J,Herrmann FR,Burkhard PR, Bouras C, Kovari E.2013. Parkinsonism and Related Disorders. Elsevier. 19;864-868

11. Jin Lin S, Baumeister T, Garg S, J McKeown M. Cognitive profiles2018 and hub Vulnerability in Parkinson's disease. Frontiers in Neurology. Vol 9.482

12. Llorens F, Villar-pique A, Candelise N, FerrerI, zerr I, 2018. Tau Protein as a biological fluid biomarker in neurodegenerative dementias.cognitif disorder journal. Chapter 4.

13. Lukasiewicz JC, Malodobra MM, Zimny A, Noga L, Paradowski. 2020. Plasma tau protein and A $\beta 42$ level as a marker of cognitive impairment in patients with parkinson's disease. Advances clinical and experimental medicine;29 (1): 115121.

14. Maiti P, Manna J, Dunbar GL.2017. Current Understanding of The Molecular Mechanism in Parkinson's Disease: Targets for potential treatments.In Translational Neurodegeneration.6;28. .pp 1-35

15. Mayza A and Lastri DN. 2017. Neurobehavior dasar dan pemeriksaannya. In Buku Ajar Neurologi.Penerbit Kedokteran Indonesia. Jakarta.vol 1

16. Mollenhauer B, 2016. Biological counfounders for the values of cerebrospinal fluid proteins in parkinson's disease and related disorders. Journal of neurochemistry. 10.1-28

17. Montine TJ, Shi M, Quinn JF,Pesking ER, Craft S, Ginghina $\mathrm{C}$, et al. 2010. CSF A $\beta_{42}$ and tau in Parkinson's disease with cognitive impairment. Journal of Mov Disord.25(15);2682-2685

18. Painous C,Marti MJ, 2020. Cognitive impairment in Parkinso's disease: What we know so far?.Research and reviews in parkinsonism 2020:10. Pp 7-17

19. Papagno $\mathrm{C}$ and Trojano Luigi, 2017. Cognitive and behavioral disorders in Parkinson's disease: Un Update. I: Cognitive Impairments. 
Review article. Springer

20. Porowska AM, Wasik U,Goras M,Filipek A, Niewiadomska G. 2014. Tau Protein Modification and Interaction: Their Role in Function and dysfunction. International Journal of Molecular Sciences.

21. Roheger M, Kalbe E, Scarfone IL,2018. Progression of cognitive decline in parkinson's disease. Journal of parkinson's disease 8: 183193

22. Salama M, Shalash A, Magdy A, Makar M,Roushdy T, Elbalkimy M.2018. Tubulin and Tau: Possible targets for diagnosis of Parkinson's and Alzheimer's diseases. United states. Plos One journal

23. Siciliano M, De Micco R, Trojano L, De stevano M, Baiano C, Passaniti C et al. 2017. Cognitive impairment is associated with Hoenh and yahr stage in early, de novo Parkinson disease patient. Parkinsonism and related disorders. Elsevier.xxx pp 1-6.

24. Tarukbua FR, Tumewah R, Maja J.2016. Overview of Cognitive Function of Parkinson's sufferers in the neurological polyclinic of Prof. Dr.R.D.Kandou Manado General Hospital. Journal e clinic volume 4

25. Wan Mohamad WNA, Che Din N, Ibrahim N. 2015. Cognitive profiles in parkinson's disease and their correlation with dementia, anxiety and depression: A preliminary study. Malay $\mathrm{J}$ Med.Dec 2015: 29-35

26. Watson GS and Leverenz JB. 2011. Profil of cognitiv impairment in Parkinson disease. $\mathrm{NIH}$ Public Access.PMC 